\title{
ORAL AND DEPOT PROGESTIN THERAPY FOR ENDOMETRIOSIS: TOWARDS A PERSONALIZED MEDICINE
}

\section{Laura BUGGIO, Edgardo SOMIGLIANA, Giussy BARBARA, Maria Pina FRATTARUOLO \& Paolo VERCELLINI}

To cite this article: Laura BUGGIO, Edgardo SOMIGLIANA, Giussy BARBARA, Maria Pina FRATTARUOLO \& Paolo VERCELLINI (2017): ORAL AND DEPOT PROGESTIN THERAPY FOR ENDOMETRIOSIS: TOWARDS A PERSONALIZED MEDICINE, Expert Opinion on Pharmacotherapy, DOI: $10.1080 / 14656566.2017 .1381086$

To link to this article: http://dx.doi.org/10.1080/14656566.2017.1381086

Accepted author version posted online: 15

Sep 2017.

Submit your article to this journal $₫$

View related articles ๘

View Crossmark data $₫$ 


\section{ORAL AND DEPOT PROGESTIN THERAPY FOR ENDOMETRIOSIS:} TOWARDS A PERSONALIZED MEDICINE

Laura BUGGIO, M.D. ${ }^{\mathrm{a}, \mathrm{b}}$ buggiolaura@gmail.com ORCID ID: 0000-0002-1199-1888

Edgardo SOMIGLIANA, M.D..$^{\text {b, }}$ dadosomigliana@yahoo.it ORCID ID: 0000-0002-0223-0032

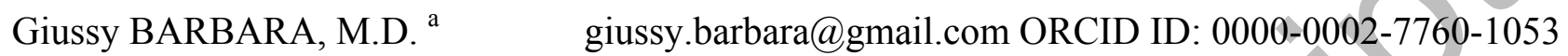
Maria Pina FRATTARUOLO, M.D. ${ }^{\text {a,b }}$ mp.frattaruolo@gmail.com Paolo VERCELLINI, M.D. ${ }^{\mathrm{a}, \mathrm{b}}$ paolo.vercellini@unimi.it ORCIDID:0000-0003-4195-0996

From the

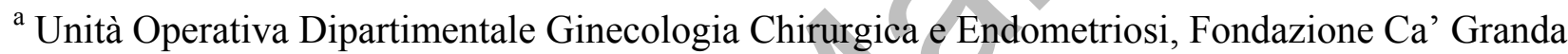
Ospedale Maggiore Policlinico, Milan, Italy

${ }^{\mathrm{b}}$ Department of Clinical Sciences and Community Health, Università degli Studi di Milano, Italy ${ }^{\mathrm{c}}$ Infertility Unit, Fondazione Ca' Granda, Ospedale Maggiore Policlinico, Milan, Italy.

Correspondence: Edgardo Somigliana, M.D.

Infertility Unit, Fondazione Ca' Granda, Ospedale Maggiore Policlinico, Milan, Italy, Via Fanti, 6 20122 Milan, Italy

Tel: +39.02.5503.4304; fax: +39.02.50320264; e-mail: dadosomigliana@yahoo.it

Funding: This paper was not funded

Declaration of interest: E Somigliana reports grants from Ferring and Serono, outside the submitted work; The authors have no other relevant affiliations or financial involvement with any organization or entity with a financial interest in or financial conflict with the subject matter or materials discussed in the manuscript apart from those disclosed. 


\section{ABSTRACT}

Introduction: Endometriosis is an estrogen-dependent chronic inflammatory disorder that requires a life-long management plan. Long-term adherence to treatment is pivotal to ensure an effective clinical management. In this optic, one of the cornerstone of endometriosis medical treatment is represented by progestins.

Areas covered: This narrative review examines the clinical efficacy, safety and tolerability of oral and depot progestins used in the treatment of endometriosis. The material included in the current manuscript was obtained with a MEDLINE search through PubMed from inception until January 2017.

Expert opinion: Progestins are effective in controlling pain symptoms in the majority of women with endometriosis, and their effect seems not inferior to that achieved with other compounds used to treat the disease, such as gonadotropin-releasing hormone agonist. Available progestins include a broad range of both oral and depot compounds, and represent, in most cases, an inexpensive treatment option. In addition, progestins do not increase significantly thrombotic risk and could be adopted in those women with metabolic or cardiovascular contraindication to estrogen-progestins. The choice between the different available compounds should be tailored for every woman with preference to the most cost-effective treatment, depending on the most complained symptom and disease location.

KEYWORDS: desogestrel; dienogest; endometriosis; levonorgestrel-intrauterine device; medroxyprogesterone acetate; medical therapy; norethisterone acetate; progestin 


\section{INTRODUCTION}

Endometriosis is a chronic inflammatory gynecological disorder associated with pelvic pain symptoms and infertility [1]. Endometriosis affects about 5\% of women of reproductive age [2].

Women with endometriosis are at increased risk of abdominopelvic chronic pain, dysmenorrhea and deep dyspareunia compared to controls without the disease [3]. The origin of pain associated with endometriosis can be referred to different pathogenic mechanisms, such as increased production of pro-inflammatory cytokines and growth factors by activated macrophages and other cells associated with endometriotic implants, active bleeding from endometriotic lesions, and irritation or direct invasion of pelvic floor nerves by infiltrating endometriotic implants $[4,5]$.

As suggested by the Practice Committee of the American Society for Reproductive Medicine (ASRM): “endometriosis should be viewed as a chronic disease that requires a life-long management plan with the goal of maximizing the use of medical treatment and avoiding repeated surgical procedures" [6]. However, patients with endometriosis represent an extremely heterogeneous population regarding both symptoms severity and anatomic abnormalities [1]. In addition, not only the efficacy, but also the long-term tolerability and costs of the treatments should be taken into account. Long-term adherence to treatment is pivotal to ensure an effective clinical management. In this optic, a tailored patient management appears of primary importance, with the aim of identifying the specific issue and the appropriate treatment for every woman.

One of the cornerstone of endometriosis medical treatment is represented by progestins [1]. Progestins are synthetic compounds that mimic the effects of progesterone [7]. They can inhibit inflammatory pathways and responses, and provoke apoptosis in endometriotic cells [8]. In addition, progestins are able to reduce oxidative stress, through the reduction or the abolishment of uterine bleeding [9]. Moreover, this class of drug stimulate atrophy or regression of endometrial lesions, induce anovulation, inhibit angiogenesis, and decrease expression of matrix metalloproteinases, thus diminishing the invasiveness of endometriotic implants $[7,10]$. Finally, 
they reduce the frequency and augment the amplitude of pulsatile gonadotropin-releasing hormone $(\mathrm{GnRH})$ release; this leads to a reduced secretion of follicle-stimulating hormone (FSH) and luteinizing hormone ( $\mathrm{LH})$ [7] with the establishment of a hypo-estrogenic milieu that could suppress endometriosis and prevent progression of the disease [10].

Numerous progestins compounds are used in the treatment of endometriosis; they can be administered via an oral, intramuscular/subcutaneous, intrauterine or subdermal route [1] (Table 1). In the endometriosis field, progestins are increasingly used as a monotherapy with great results $[1,10]$. Major advantages of these drugs are that they do not increase the thrombotic risk and can be safely used in those women with contraindication to estrogens [11] or in those who do not tolerate estrogens [12].

\section{METHODOLOGY}

In this narrative review, we aimed to provide a comprehensive overview of the role of both oral and depot progestins in the treatment of endometriosis, analyzing the pros and cons of every compound. We have included in our manuscript only those progestins specifically adopted for the treatment of endometriosis. For this review, the best quality evidence was selected with preference given to the most recent and definitive original articles and reviews. Information was identified by searches of MEDLINE and references from relevant articles, using combinations of MESH terms “endometriosis", "progestin", "progestin therapy", "medical therapy”, “norethisterone acetate”, "norethindrone acetate", "dienogest", "desogestrel”, "cyproterone acetate", "medroxyprogesterone acetate", "depot medroxyprogesterone acetate", "levonorgestrel intrauterine device", and “etonogestrel". The search was limited to peer-reviewed, full-text articles in the English language. For most issues, papers published between June 1989 and February 2017 were considered. 


\section{ORAL PROGESTINS}

\subsection{NORETHISTERONE ACETATE}

Norethisterone acetate (or norethindrone acetate, NETA) is a strong derivative of 19-nortestosterone. Continuous use, at the lowest dose of $5 \mathrm{mg} / \mathrm{d}$, is approved by the US Food and Drug Administration (FDA) for the treatment of endometriosis. However, numerous studies by independent groups demonstrated the efficacy of a reduced daily dose of $2.5 \mathrm{mg}$ [13-16]. The lower dosage increases the tolerability, reducing weight gain and androgenic side effects, and limits the negative impact on serum cholesterol values [13]. In addition, NETA is partly metabolized to estrogens [17,18], with subsequent positive effects on bone metabolism. Another major advantage of NETA is its cost, in fact, in Italy, the monthly cost of treatment with $2.5 \mathrm{mg} / \mathrm{d}$ is less than 2 US \$ [13].

Several studies demonstrated the beneficial effects of NETA in the management of symptomatic endometriosis. In 1998 Muneyyirci-Delale and Karakan [19] treated 52 women with surgically confirmed endometriosis with NETA at a daily dosage of $5 \mathrm{mg}$, which was increased by $2.5 \mathrm{mg}$ up to $20 \mathrm{mg} / \mathrm{d}$ until amenorrhea was obtained. Overall, pain relief was achieved in 49/52 $(94 \%)$ of patients, with a discontinuation rate of $15 \%(n=8)$. The most common side effect was breakthrough bleeding, reported by 30 women (58\%), that led to drop out in $4(8 \%)$ patients.

The favorable impact of NETA on endometriosis symptoms was confirmed by Vercellini et al. [13] in a randomized trial comparing NETA, at a daily dosage of $2.5 \mathrm{mg}$, and an estrogenprogestin (EP) combination (ethinyl estradiol (EE) $0.01 \mathrm{mg}+$ cyproterone acetate $3 \mathrm{mg}$ ). Both therapies were administered continuously for 12 months. Only patients with symptomatic rectovaginal endometriosis were enrolled $(n=90)$. Overall, $73 \%$ women in the NETA group were satisfied or very satisfied with treatment compared to $62 \%$ in the EP group. Both treatments were equally effective in the management of pain symptoms and on the reduction of lesion size at ultrasound. Both regimens caused minor unfavorable changes in the serum lipid profile. Weight 
gain $(27 \%$; mean weight gain $3.6+/-2.3 \mathrm{~kg})$ and decreased libido $(9 \%)$ were the most frequent reported side effects in NETA treatment group.

In 2010, Ferrero et al. [14] performed a pilot study on the efficacy of NETA in the treatment of pain and gastrointestinal symptoms in 40 women with colorectal endometriosis. Patients received NETA $2.5 \mathrm{mg} / \mathrm{d}$ for 12 months, in case of persistent breakthrough bleeding patients were instructed to increase the dose to a $5 \mathrm{mg} / \mathrm{d}$. The satisfaction rate was good $(60 \%)$, more than half of the patients reported an improvement in gastrointestinal symptoms and an amelioration of chronic pelvic pain and deep dyspareunia. The study was completed by 32 patients $(80 \%)$, the most frequent cause of interruption was weight gain $(n=2 ; 5 \%)$.

Kaser et al. [20] successfully tested NETA in a population of adolescents and young adults ( $n=194)$ with histologically confirmed endometriosis. In this retrospective study, women were treated with higher dose of NETA $(5-15 \mathrm{mg} / \mathrm{d}) .65 \%$ of the patients reported a reduction in pain scores. Confirming previous data, the most common side effect associated with NETA administration was weight gain (16\%).

In 2012, continuous low-dose progestin therapy (NETA $2.5 \mathrm{mg} / \mathrm{d}$ ) and surgical therapy for endometriosis-associated deep dyspareunia were compared in a patient-preference parallel cohort study with a 12-month follow-up $[15,16]$. Only women with severe deep dyspareunia were enrolled. A total of 154 patients were included in the study, 51 chose surgery and 103 progestin treatment. In the surgery group dyspareunia's improvement was marked and rapid, followed by partial recurrence of pain. Instead, in progestin group pain relief was more gradual but progressive throughout the whole study period. In addition, at the end of follow-up, patients treated with medical therapy reported a greater increase in the frequency of intercourse per month. Satisfaction rate was statistically significantly higher in the progestin group (59\% versus 43\%). At 1-year follow-up, NETA performed better than surgery in women without deep lesions, whereas in those with rectovaginal endometriosis, the two treatments showed comparable efficacy [15]. One of the major 
drawbacks and potential source of selection bias of this study is the non-random allocation of treatments, as the choice between surgery and medical treatment was based on patient's preference.

Progestin therapies with NETA and dienogest (DNG) were directly compared by Vercellini et al. in 2016 [21]. The authors chose a before-after study design, in order to investigate the effectiveness (which of the two compounds performed better in real life) of the treatments. NETA has been shown to be as effective as DNG for pain relief, psychological status, sexual functioning and health-related quality of life (QoL). The proportion of satisfied plus very satisfied women after 6 months of treatment was almost identical between the two study groups $(71 \%$ in NETA group versus $72 \%$ in DNG group). In this Italian study, DNG was better tolerated than NETA, but much higher cost limited its acceptance by the patients.

\subsection{DIENOGEST}

Dienogest (DNG) is a fourth-generation selective progestin that combines the pharmacological properties of 19-nortestosterone and of progesterone derivatives. When administered at the dosage indicated for the management of endometriosis $(2 \mathrm{mg} / \mathrm{d})$, DNG inhibits the production of gonadotropin with a decrease in the endogenous release of estradiol, with the establishment of a hypoestrogenic and hyperprogestinic environment that stimulates initial decidualization and subsequent atrophy of endometriotic lesions [22]. However, during DNG treatment (at a daily dose of $2 \mathrm{mg}$ ) the average estradiol $\left(\mathrm{E}_{2}\right)$ serum levels remain in the range of $20-50 \mathrm{pg} / \mathrm{ml}$; this $\mathrm{E}_{2}$ serum concentration should, at the same time, prevent bone mineral density (BMD) loss and avoid endometriotic lesions growth [22]. Moreover, DNG exerts strong antiandrogenic properties, whereas it has no glucocorticoid nor mineral corticoid effects [22,23].

However, regarding bone mineral density (BMD), the available data are inconsistent. In a recent study Lee et al. [24] have compared DNG (2 mg/d) with gonadotropin-releasing hormone agonist (GnRHa) with add-back (NETA $0.5 \mathrm{mg} / \mathrm{d}$ or estradiol $1 \mathrm{mg} / \mathrm{d}$ ) therapy for the treatment of 
endometriosis reporting a decline BMD at the lumbar spine in both treatment groups $(-2.3 \%$ for DNG and $-2.5 \%$ for GnRHa plus add-back). These data are in line with those of Momoeda et al. [25] that showed a significantly decrease (-1.6\%) of lumbar spine BMD after 24 weeks of DNG treatment in patients with endometriosis. On the contrary, Strowitzki et al. [26] observed minimal changes in bone turnover markers and lumbar spine BMD after 6 months of DNG treatment.

DNG clinical efficacy has been investigated in studies against placebo [27], GnRH analogs [24,26,28-30], oral medroxyprogesterone acetate [31], and NETA [21,32] (Table 2). No randomized controlled trials (RCTs) assessing the effectiveness of DNG compared with combined oral contraceptives or with other progestins have been performed. Overall, a daily dose of $2 \mathrm{mg}$ DNG has been significantly better than placebo in relieving pelvic pain and dysmenorrhea related to endometriosis and as effective as GnRH agonist therapy in relieving pain [33].

In 2014, Morotti et al. [32] evaluated patients' satisfaction after 6 months of treatment with DNG in 25 symptomatic women with rectovaginal endometriosis, who were non-responders to NETA. DNG performed better than NETA both in terms of pain relief and in terms of improvement of quality of life and quality of sexual life, evaluated, respectively, with the EHP-30 and FSFI questionnaires. No changes of volume of the rectovaginal plaques (endometriosis infiltrating the posterior vaginal and anterior rectal walls) were observed during treatment with DNG. These encouraging results were not confirmed in the comparative study between NETA and DNG that was discussed above [21].

The beneficial role of DNG in the improvement of QoL and sexual functions in women with symptomatic endometriosis has been confirmed by Caruso et al. [34], who enrolled 102 endometriotic patients, assigning them to DNG treatment $(n=54)$ or non-steroidal antiinflammatory drugs $(n=48)$, the study period lasted 6 months. Patients were evaluated after 3(first follow-up) and 6-months of treatment. Women in DNG group reported a significant amelioration compared to control group in pain symptoms and QoL at the first follow-up, and in 
sexual life at the second follow-up. This latter element could be attributable to a progressive reduction of deep dyspareunia and pelvic pain.

Another field of application of DNG treatment is bladder endometriosis. A recent pilot study [35] on six patients treated for 12 months with DNG $2 \mathrm{mg} / \mathrm{d}$ showed an improvement of pain symptoms in all patients. In particular, urinary symptoms disappeared and at transvaginal ultrasound a significant decrease of bladder nodule size at 3- and 12-months evaluation was described. The potential beneficial effect of DNG on extragenital endometriosis has been evaluated in a small Japanese case series [36], in which four women with rectoisigmoidal endometriosis and one with bladder disease were enrolled. All patients received DNG at the standard daily dosage (2 $\mathrm{mg} / \mathrm{d}$ ) for over 6 months. For all cases, a relief in pain symptoms and a lesion size reduction at ultrasonography were confirmed at follow-up.

Finally, a recent prospective study [37] evaluated the effectiveness of DNG on 30 patients with deep infiltrating endometriosis. After one year of treatment there was a significant improvement in all pain symptoms, including deep dyspareunia, without a reduction in the volume of endometriotic lesions at transvaginal sonography.

The safety and efficacy of long-term use (52 weeks) of DNG at a daily dose of $2 \mathrm{mg}$ have been investigated in a multicenter Japanese study on 135 patients with endometriosis [25]. The most common adverse effects observed during treatment were menorrhagia $(71.9 \%)$, headache $(18.5 \%)$, and constipation $(10.4 \%)$. The severity of menorrhagia was mild in the majority of women $(n=82)$ and moderate in 15 cases. Breakthrough bleeding was the cause of two of the discontinuations and 11 washouts. During the study period, there was a progressive decrease of abnormal bleeding, indicating a tendency to amenorrhea with the extension of the treatment period. In a pooled analysis of four randomized, controlled, European trials [38] the most common adverse reactions were headache (9\%), breast discomfort (5.4\%) depressed mood (5.1\%), and acne (5.1\%). The bleeding pattern was well-tolerated, and only the $0.6 \%$ of the enrolled women reported bleeding events as the 
main cause for premature discontinuation. In addition, no significant variations were registered in serum levels of lipids, glycated hemoglobin and estradiol. These results were in line with those observed by Schindler et al. [39], whose study analyzed the safety of high-dose (20 mg/day) treatment with DNG for 24 weeks. Overall, DNG is a well-tolerated drug with a rate of discontinuation related to adverse reactions $<5 \%[22]$.

The principal limitation to the widespread use of DNG as first-line treatment for endometriosis is its cost, higher than other progestins and combined oral contraceptive (COC) available on the market. In fact, in Italy, the annual cost of treatment with $2 \mathrm{mg} / \mathrm{d}$ of DNG is about 770 US \$. Moreover, further studies should compare the efficacy of this drug with other progestins.

\subsection{DESOGESTREL}

Desogestrel (DSG) is a third-generation 19-nortesterone derivative progestin. DSG is a prodrug, which after oral administration is absorbed and converted to its active metabolite, Etonogestrel (ETN). The effects of DSG progestin-only pill (POP) on lipid and carbohydrate metabolism and hemostasis are derived from studies of comparison with levonorgestrel POPs [40] and showed a slight decrease of HDL-cholesterol, a minimal impact on carbohydrate metabolism, and a reduction of pro-coagulative activity. DSG-POP represents a safe contraceptive method (monthly ovulation is inhibited in $97 \%$ of users), and can be used during breastfeeding [41].

Few studies investigated the role of DSG in the treatment of endometriosis [42-45]. In 2007 [42], continuous treatment with DSG-POP $(75 \mu \mathrm{g})$ was compared to a COC (EE $20 \mu \mathrm{g}+$ DSG150

$\mu \mathrm{g}$ ) for the treatment of 40 women with laparoscopically confirmed mild endometriosis (stage I and II). After 6 months of treatments, a significant improvement of pelvic pain was observed in both study groups, without between-group differences. The principal side effect reported in DSG group was breakthrough bleeding $(4 / 20 ; 20 \%)$. The combination of DSG-POP and letrozole $(2.5 \mathrm{mg} / \mathrm{d})$, an 
aromatase inhibitor, for the treatment of stage IV endometriosis was tested in an open-label, prospective study [43]. A total of 12 women with persistent pelvic pain, not responding to previous surgical and medical therapy, were enrolled. Unfortunately, none of the patients completed the 6months treatment protocol, due to the development of functional ovarian cysts, with a median length of treatment of 84 days (range 56-112). This secondary effect could be ascribable to aromatase inhibitors. In fact, these compounds, block the conversion of androgens to estrogens in ovarian granulosa cells, with a consequent reduction of the negative feedback at the pituitaryhypothalamus level, and therefore, increasing serum follicle-stimulating hormone levels that favor the growth of ovarian follicles [43]. During treatment, all the patients reported a significant improvement of dyspareunia and an amelioration of chronic pelvic pain. According to previous study the main adverse reaction was abnormal bleeding (75\%), followed by weight gain (50\%) and abdominal bloating (42\%). In 2014, a patient preference trial [44] compared the contraceptive vaginal ring (EE $15 \mu \mathrm{g}+$ etonogestrel $120 \mu \mathrm{g}$ ), administered cyclically, to the DSG-POP (75 $\mu \mathrm{g} / \mathrm{d})$ for the treatment of symptomatic women with rectovaginal endometriosis. The treatment period lasted 12 months; 60 women chose the DSG-only pill and 83 the vaginal ring. At the end of the study, the rate of satisfied women was higher in the group treated with DSG-POP $(61.7 \%$ vs. $36.1 \%$ ). The discontinuation rate and the reduction in volume of rectovaginal nodules were similar in the two study groups, Gastrointestinal symptoms, chronic pelvic pain and deep dyspareunia were improved more in the DSG-POP group. Finally, a second patient preference trial [45] evaluated patient satisfaction after 6 months of treatment with DSG-POP $(75 \mu \mathrm{g} / \mathrm{d})$ and cyclic COC (EE $20 \mu \mathrm{g}$ + DSG $150 \mu \mathrm{g}$ ) in patients with symptomatic rectovag,inal endometriosis and migraine without aura. 62 women chose the DSG-only pill and 82 the COC, the withdrawal rate was higher in the COC group (24.4\% versus $11.3 \%$ ); the main cause of interruption in DSG-POP group was erratic bleeding $(n=5 ; 8 \%)$. Satisfaction rate was higher in POP group (61.2\% versus $37.8 \%)$, a significant improvement in QoL, both in terms of mental and physical components, was demonstrated with DSG treatment. In addition, the severity and number of migraine attacks were significantly different 
between baseline and 6-month treatment in POP group $(P<0.001)$ but not in COC group $(P=$ 0.078). Regarding pain symptoms both treatments were equally effective.

\subsection{CYPROTERONE ACETATE}

Cyproterone acetate, a 17-hydroxyprogesterone derivative with antiandrogenic and antigonadotropic properties, represents one of the first progestins adopted for the treatment of endometriosis. In 1996, Moran et al. [46] performed a pilot study on seven women with laparoscopically confirmed endometriosis, with the aim of evaluating the effectiveness of a 6-month cyclical cyproterone acetate regimen $(10 \mathrm{mg} / \mathrm{d}$ for 20 days, followed by 10 days without medication). Dysmenorrhea improved in all study subjects. At the end of the treatment, a secondlook laparoscopy showed an amelioration of the endometriosis stage. Finally, a RCT [47] compared the efficacy and safety of low-dose cyproterone acetate $(12.5 \mathrm{mg} / \mathrm{d})$ versus a COC $(\mathrm{EE} 0.02 \mathrm{mg}+$ DSG $0.15 \mathrm{mg}$ ). Both treatments were administered continuously for 6 months. Ninety patients with recurrent moderate or severe pelvic pain after conservative surgery for endometriosis were enrolled. Overall, at the end of treatment, $73 \%$ of the women in the cyproterone acetate group were satisfied or very satisfied compared with $67 \%$ in the COC group. Both treatments were equally effective in reducing pain symptoms and enhancing QoL and sexual satisfaction. The withdrawal rate was similar (nine and six patients); the main side effects causing suspension of the treatment in the cyproterone acetate group were bloating $(n=1)$, decreased libido $(n=1)$, depression $(n=1)$, and headache $(n=1)$. Interestingly, seven women in the cyproterone acetate group reported a substantial reduction in libido, probably due to the antiandrogenic properties of the compound. The mean weight gain was comparable between the two study groups $(2.4 \pm 0.5 \mathrm{~kg}$ in the progestin group versus $2.2 \pm 0.4 \mathrm{~kg}$ in the COC group). Regarding blood pattern, amenorrhea was reached in two thirds of women under progestin therapy and in about half of those taking COC. No major variations in serum lipid profiles were detected in either study group. 


\section{DEPOT PROGESTINS}

\subsection{DEPOT MEDROXYPROGESTERONE ACETATE (DMPA)}

Medroxyprogesterone acetate is a $17 \mathrm{OH}$-progesterone derivative available as a depot formulation (DMPA), which can be administered intramuscularly or subcutaneously every three months. DMPA is a highly effective and inexpensive contraceptive method that has been adopted worldwide for several decades [48].

First evidence of the use of DMPA for the treatment of endometriosis are dated back 1996, when Vercellini et al. [49] performed a RCT comparing intramuscular DMPA (150 mg/3 months) to a combination of cyclic COC and low-dose oral danazol $(50 \mathrm{mg} / \mathrm{d})$ for the treatment of pelvic pain in women with endometriosis. The compounds were administered for one year; a total of 80 women were enrolled, 40 subjects were allocated in each study group. Overall, at the end of treatment, $72.5 \%$ of the women in the DMPA group were satisfied or very satisfied compared with $57.5 \%$ in the COC plus danazol group. A significant decrease was demonstrated in all symptoms scores in both study groups without significant between-group differences. A total of eleven women withdrew from the study (four in DMPA group and seven in COC plus danazol group). The main side effects in DMPA arm concern menstrual pattern, with eight women out of ten reporting breakthrough bleeding (15\%) and spotting (65\%). In addition, the median time to return of regular menstrual flow in women who received DMPA was seven months, with a maximum delay of 1 year. Finally, in both arms, a significant reduction in high-density lipoprotein cholesterol was observed.

Two large multicenter, evaluator-blinded, comparator-controlled trial [50,51] confront subcutaneous administration of DMPA $104 \mathrm{mg} / 0.65 \mathrm{ml}$ (DMPA-SC) with leuprolide acetate, given every three months for six months, with 12 months of post-treatment follow-up. In both studies DMPA-SC was statistically equivalent to GnRHa in reducing pain symptoms after 12 months' 
follow-up. Significant improvements in QoL, evaluated through EHP-30 and SF-36 scales, occurred in both treatment groups. Moreover, women in DMPA-SC arm referred a significant amelioration in their sexual relationship at month 6 [50]. Patients in the DMPA-SC group showed significantly less BMD loss than did leuprolide patients at month 6. In addition, BMD levels return to pretreatment levels at 12 months' follow-up in the DMPA-SC group but not in the leuprolide group. Regarding side effects, DMPA-SC was associated with fewer hypoestrogenic symptoms but more irregular bleeding, varying from light spotting to uterine hemorrhage. However, the discontinuation rate secondary to adverse events was low (2\% in DMPA-SC group and 1.4\% in leuprolide group) [50].

A RCT compared intramuscular DMPA (150 mg/3 months) with levonorgestrel-releasing intrauterine system (LNG-IUS) for the treatment of patients with moderate and severe endometriosis [52]. A total of thirty patients after conservative surgery for endometriosis underwent randomization; the treatment period lasted three years. A lumbar and hip DEXA scan was repeated yearly. Both treatments were effective in the management of pain symptoms through the study period. The only domains where no amelioration was observed were dyspareunia and urinary/bowel symptoms. No recurrences of lesions were detected at transvaginal ultrasound in both therapeutic groups. The drop-out rate was higher in DMPA group (53\% versus 13\%). The two main causes of discontinuation among the eight patients that interrupted DMPA were prolonged vaginal spotting $(n$ $=3)$ and significant bone loss over lumbar spine $(n=2)$.

One of major sources of concerns regarding prolonged use of DMPA is the decrease of BMD and the increase risk of fracture, due to estrogen deficiency accompanying its use. Several studies have reported a reduction in BMD in DMPA users [53-62]. The greatest loss occurs during the first two years of treatment, and then BMD levels become stable [63-65]. In 2004, the FDA published a "black box warning" [66], and the Health Canada issued an advisory [67], recommending providers to adopt DMPA only if other methods were unsuitable or unacceptable and to limit its use to the shortest time possible, limiting its maximum use to 2 years. However, the 
reversibility of the negative impact of DMPA on BMD toward or to baseline values within two years after discontinuation has been demonstrated in numerous studies $[59,61,65,68]$. Regarding the risk of fracture, two large-scale, population-based, case-control studies $[69,70]$ showed a modest increase in the risk in DMPA users, particularly in long term users (ORs $\leq 1.5)$. These results were not confirmed in a large retrospective cohort study on more than 1.7 million women-years [71]. Further studies are needed to estimate the effect of DMPA use on the risk of fractures. Despite these premises, according to the American College of Obstetricians and Gynecologists (ACOG) [48] and WHO recommendations [72] the benefits of DMPA use surpasses the risks.

\subsection{LEVONORGESTREL-RELEASING INTRAUTERINE SYSTEM (LNG-IUS)}

The LNG-IUS releases levonorgestrel, a potent 19-nortesterone derivative, directly into the uterine cavity at a relatively constant rate of $20 \mu \mathrm{g}$ /day over a 5-year period [73]. The LNG-IUS induces profound effects on the eutopic endometrium, which became atrophic and inactive, whereas ovulation is usually not inhibited [74]. In fact, anovulatory rates varies from $70-85 \%$ in the first months of use to $15-40 \%$ after that [75]. The plausible mechanisms at the basis of LNG-IUS use in endometriosis field comprehend the induction of endometrial glandular atrophy, an extensive decidual transformation of the stroma, the downregulation of endometrial cell proliferation, and the intensification in apoptotic activities [74]. Moreover, the ameliorative effects of LNG-IUS on endometriosis' symptoms are likely modulated through a decrease in the expression of glandular and stromal estrogen ( $\alpha$ and $\beta$ ) and progesterone receptors in the ectopic endometrium [76, 77]. In addition, LNG-IUS increased Fas expression in both eutopic and ectopic endometrium of patients with endometriosis [76].

One of the first studies evaluating the effectiveness of LNG-IUS in the treatment of endometriosis was performed on 11 women with symptomatic rectovaginal endometriosis [78]. At 1-year follow-up the severity of all pain symptoms, including deep dyspareunia and dyschezia, 
improved. Rectovaginal lesions size, evaluated through transrectal and transvaginal ultrasound, was significantly reduced after six months of therapy.

Moreover, the LNG-IUS has been evaluated in numerous RCTs for the treatment of symptomatic endometriosis (Table 3), with positive results. In particular, a Brazilian multicenter trial [80] compared the efficacy of the LNG-IUS and a depot GnRHa in 82 women with symptomatic endometriosis. At 6-months follow-up both treatments appeared to be similarly effective for endometriosis-related chronic pelvic pain, with a six-points decrease from baseline in VAS pain score in both study groups. At the end of the study, the $13 \%(n=5)$ of patients in the LNG-IUS group and the $14 \%(n=6)$ in the GnRHa group failed to reach a VAS pain score of less than three. In both treatment groups, the subgroup of patients that achieved the more rapid improvement in VAS score was the one of patients with stage III and IV of the disease.

The long-term efficacy of LNG-IUS in the management of endometriosis has been evaluated in a retrospective study [85], that showed the ability of the device in providing symptoms control throughout a 3-year study period. These results are in line with those obtained in a RCT [52] that compared LNG-IUS with DMPA in the long-term treatment (36 months) of patients with moderate and severe endometriosis.

As above mentioned, in the majority of patients, LNG-IUS is unable to suppress ovulation, raising concerns for the risk of endometrioma recurrence, in line with the theory of endometriomas originating from corpora lutea [86]. Moreover, women treated with the device are prone to develop functional ovarian cysts [87] that could be misdiagnosed with ovarian endometriomas. Few studies have evaluated the long-term effectiveness of the device for the prevention on endometrioma recurrence. In the RCT of Wong et al. [52] no recurrences were identified; however, the sample size was small $(n=15)$ and the number of patients that continued the study throughout the whole followup period was even minor $(n=13)$. These outcomes are superimposable to those obtained by Tanmahasamut et al. [83], that did not identify any endometrioma recurrence after 12 months of 
treatment with LNG-IUS. Two retrospective studies [88,89] compared the efficacy of postoperative use LNG-IUS with COC for preventing endometrioma recurrence. In both cases, postoperative LNG-IUS use seems comparable to that of COC in preventing endometrioma recurrence. On the contrary, another retrospective study [90] reported a cumulative postoperative endometrioma recurrence rate of 25\% at 5-year follow-up. Accordingly, a recent RCT [84] showed a comparable endometrioma recurrence rate at 30-months' follow-up between women allocated in LNG-IUS group $(10 / 40,25 \%)$ and those in the expectant management group (15/ 40, 37.5\%) (95\% confidence interval: $0.27-1.33, P=0.2$ ). In both study groups, patients received an initial treatment, after laparoscopic cystectomy, with six cycles of GnRHa. The number of recurrent endometriotic cysts necessitating a second surgical intervention or hormone treatment was significantly higher in the control group $(8 / 40,20 \%$ versus $1 / 40,2.5 \%)$. In line of recent evidence, we believe that the potential role of LNG-IUS in the prevention of endometrioma recurrence should be reconsidered, and an appropriate counseling with the patient on this risk is the needed prior to device insertion.

Therefore, the best candidates for this treatment modality seem to be women who have already completed their family project or wish to postpone pregnancy, whose main symptom is dysmenorrhea, who are in their forties, and who do not tolerate progestins used systemically [1]. Moreover, women should be informed that during the first months of treatment, significant menstrual bleeding abnormalities, including spotting and even menorrhagia, are expected. Whereas, after the first year of use, almost 20-30\% of patients became amenorrheic [74].

\subsection{ETONOGESTREL SUBDERMAL IMPLANT}

The etonogestrel (ENG) subdermal contraceptive implant is a device containing $68 \mathrm{mg}$ of ENG and is currently approved by the FDA for three years of use. Recent data suggest extended contraceptive efficacy to at least five years $[91,92]$. The implant should be inserted sub-dermally in the upper arm. 
Few data are available on the use of this device for the treatment of endometriosis and the majority came from case reports and case series [93-95]. In 2005, Ponpuckdee et al. [96] evaluated the efficacy of ENG-subdermal implant in the treatment of fifty symptomatic women with surgically confirmed endometriosis, with an improvement of pain severity and a high satisfaction rate $(80 \%)$. The follow-up lasted only 12 weeks, and 30\% of the patients reported spotting and breakthrough bleeding. Walch et al. [97] conducted a RCT with the aim of comparing the therapeutic efficacies of ENG-subdermal implant $(n=21)$ and DMPA $(n=20)$ concerning pain relief in forty-one women with symptomatic endometriosis. During the 1-year follow-up, a substantial improvement in pain intensity was recorded in both study groups; after 6-months, the average reduction in pain was $68 \%$ in the ENG-subdermal implant group and $53 \%$ in the DMPA group. The overall satisfaction rate was almost identical in the two groups (57\% in the ENG group versus 58\% in the DMPA group). The percentage of withdrawal was higher in DMPA group (35\%, $n=7)$ compared to ENG group $(19 \%, n=4)$. The principal cause of interruption in the latter group was unbearable bleeding irregularities $(n=2)$.

The effect of ENG-implant on BMD have been evaluated in a prospective comparative study in 2000 [98]. The effect of ENG-implant on BMD was compared to a non-hormone medicated IUS. Changes from baseline on the ENG-group were comparable from those in the IUS group. Contrarily, Bahamondes et al. [99] demonstrated a significantly decrease in BMD at the midshaft of the ulna after 18 months from the insertion of the device.

In March 2016, the FDA published a warning regarding the risk of migration of the implant within the arm from the insertion site, due to deep insertion of the implant [100]. In addition, there have also been post-marketing reports of implants migrated within the vessels of the arm and the pulmonary artery, which request an endovascular or surgical procedure for the removal. The FDA recommends the removal of the implant, prior identification of the site of migration if the device 
cannot be palpated. The frequency of migration of radiopaque implant is $1.3 /$ every millions of inserted devices [101].

\section{CONCLUSIONS}

Progestins therapies adopted for the treatment of endometriosis include a wide range of therapeutic options (Table 4), that appear effective in the management of pain symptoms associated with the disease but differ considerably regarding their cost and side-effects profile.

Advantages of depot preparations include avoidance of need of repeated administration, effective contraception, and absence of hepatic first-pass metabolic effect. In addition, absorption is not affected by episodes of diarrhea or vomiting and the continuous delivery maintains constant plasma drug levels and eliminates the peaks and troughs associated with the oral administration. The main disadvantage of depot compounds, contrarily to oral drugs, is the impossibility to promptly interrupt treatment in the event of adverse effects. This drawback seems particularly important in case of treatment with DMPA, where uterine breakthrough bleeding can be prolonged and difficult to correct. Moreover, with DMPA, a prolonged delay in the resumption of ovulation has been observed. Thus, this kind of treatment should be reserved for women with persistent or recurrent pain after hysterectomy for endometriosis [1].

Given the chronicity of endometriosis disease, the treatment of choice should ideally be taken until the establishment of menopause. In addition, endometriosis should not be seen as a unique disease, and a specific treatment for different endometriotic localizations should be considered. OCs may be first considered for women with endometriomas while progestins may be favored for those with deep endometriosis. This latter form of the disease deserves more careful management because of the possible clinical consequences. In fact, deep endometriosis could be defined as the truly severe endometriotic disease [1]. Noteworthy, these lesions commonly 
infiltrates into richly innervated anatomic sites, and the presence of mast cells in deep nodules is more common compared to those in ovarian and superficial peritoneal lesions [1].

It appears of fundamental importance an appropriate counseling of the patient, in order to consider patient's preference and to provide a comprehensive overview of the available treatments and their relative effectiveness, side effects, and cost. In line with this view, the economic burden represents the main obstacle to the widespread of dienogest diffusion, in spite of the good outcomes in terms of pain management. The treatment should be tailored for every woman with preference to the most cost-effective compound, depending on the most complained symptom, disease location, and the need for contraception.

In other words, the clinical approach should be more patient-oriented than drug-oriented. There is not the best drug but, conversely, the best drug for this specific woman, a drug that minimizes the side effects deemed relevant for this particular woman and that consents to ensure long-term adherence. The cornerstone of endometriosis treatment is the long-term adherence of the patient to the treatment. In this optic, side-effects, costs and effectiveness should receive equal consideration. Low costs of medication and a favorable side-effects profile can play a crucial role for long-term adherence to treatment [1,11]. Moreover, shift from one agent to another during life should not be considered a failure. Definitely abandoning medical treatment is the real failure because it exposes women to recurrences and possible demanding and risky subsequent surgeries.

\section{EXPERT OPINION}

Endometriosis can be effectively controlled even if not definitely cured. Progestins are effective in controlling pain symptoms in approximately three out of four women with endometriosis, and their effect seems not inferior to that achieved with other compounds used to treat the disease, such as GnRHa [1]. Available progestins used in the treatment of endometriosis include a broad range of 
both oral and depot compounds, and represent, in most cases, an inexpensive alternative treatment option. In addition, progestins do not increase significantly thrombotic risk and could be adopted in those women with metabolic or cardiovascular contraindication to estrogen-progestins [11].

However, many issues on medical management of endometriosis are still open and require a definitive answer, such as whether progestins are superior to estrogen-progestins, or one progestin is more effective or better tolerated than another, particularly in those patients with deep infiltrating lesions. As a matter of fact, we need more data from comparative studies among progestins in order to provide more valuable information to women. Unfortunately, this aspect has been up to now neglected (Figure 1). In addition, the efficacy (i.e., which one works better under ideal and highly controlled conditions, such as in an RCT) on the disease seems to be similar among drugs but the effectiveness (i.e., whether one drug works better than the other in real life, that is, under non-ideal circumstances) may radically differ. Of particular relevance, here is the need for real life studies. RCTs are obviously outstanding evidence, but they do not provide information on adherence. Future research should also focus on alternative routes for drug administration, such as the intravaginal one. In endometriosis field, the vagina represents a scarcely explored route for drug delivery, and the majority of available evidence came from studies on danazol and the estrogenprogestin contraceptive vaginal ring. However, advantages of the vaginal administration are several, such as the reduction of daily dosages, the continuity of drug release, the avoidance of the hepatic first-pass effect, and the possibility of extending the interval between doses, all factors that taken together could enhance patient's adherence to the drug regimen [104]. Moreover, is plausible to hypothesize that a local administration near the endometriotic nodules could result in higher concentrations of the drug in the surrounding area, with the potential result of a "target lesion" therapy.

The "definite" drug, i.e. the drug that could definitely eradicate endometriosis is not in our hands and will not be available in the next future. The main obstacle to research in this field is our 
ignorance of the real causes of the disease. Progresses have been made in our understanding of the pathogenetic mechanisms but the causes remain obscure. In fact, new options that are foreseen for the management of endometriosis act on specific pathogenetic mechanisms and are thus not expected to overcome the need for long-term use that is the most important drawback of progestins [105]. Given their inevitably extremely higher costs consequent to the financial effort for their development and the generally favorable side-effects profile of progestins, the new agents are inherently intended to become second line treatments, i.e. agents to be used when progestins are ineffective or non-tolerated.

For future studies, we plea for a radical shift of the study design for the development of new agents for endometriosis. In particular, we argue against the commonly used superiority RCTs against placebo to demonstrate effectiveness and non-inferiority RCT against GnRH analogues to support clinical relevance. Even if these type of studies are required by some main authorities such as the Food and Drug Administration (FDA) to allow registration, they are of scant clinical interest [106]. Firstly, we should remember the existence of the placebo-effect, especially on trials, whose main objective is pain relief. Therefore, blinding is mandatory for any study addressing this issue; however, we have to underline that an ideal placebo for a treatment affecting menstruation is very arduous to realize. Moreover, allocating suffering women to a placebo arm is ethically questionable, and it has already been repeatedly demonstrated that any drug is better than placebo for pain relief $[102,103]$. Secondly, one may also question the use of GnRH agonists as comparator in noninferiority trials. GnRH agonists are highly effective drugs but they cannot be administered for more than six months because of side-effects and endometriosis typically relapse once they are discontinued. A new compound that would be slightly less effective than GnRH agonists but that would consent long term safe use and even pregnancy seeking would be discarded by the FDA policy despite this advantageous profile. 


\section{ARTICLE HIGHLIGHTS}

- Endometriosis is an estrogen-dependent chronic inflammatory disorder of fertile age that requires a chronic treatment. Long-term adherence to treatment is pivotal to ensure an effective clinical management.

- Progestins act through the inhibition of inflammatory pathways and responses, provoking apoptosis in endometriotic cells. Moreover, this class of drug stimulate atrophy or regression of endometrial lesions, induce anovulation, inhibit angiogenesis, and decrease expression of matrix metalloproteinases, thus diminishing the invasiveness of endometriotic implants.

- Available progestins adopted in the management of endometriosis include a wide range of both oral and depot compounds, and represent, in most cases, an inexpensive treatment option.

- As there are not enough robust data demonstrating the superiority of one progestin over the others, the first choice should be low-dose oral norethisterone acetate, given the extremely favorable cost-effectiveness profile.

- Future researches on progestins in the treatment of endometriosis should focus on comparison trials with others progestins or estrogen-progestins, and should be designed as superiority trials. 


\section{FIGURE LEGEND}

Figure 1. Available comparative studies between progestins on endometriosis. Drugs highlighted in yellow are oral drugs. Depot agents are in blue. Black arrows indicate comparative studies. Red arrows indicate RCTs. The numbers in the circles refer to the specific publications. They are as follows: (1) Vercellini et al., 2016 [21]; (2) Morotti et al., 2014 [32]; (3) Walch et al., 2009 [97]; (4) Wong et al., 2010 [52]

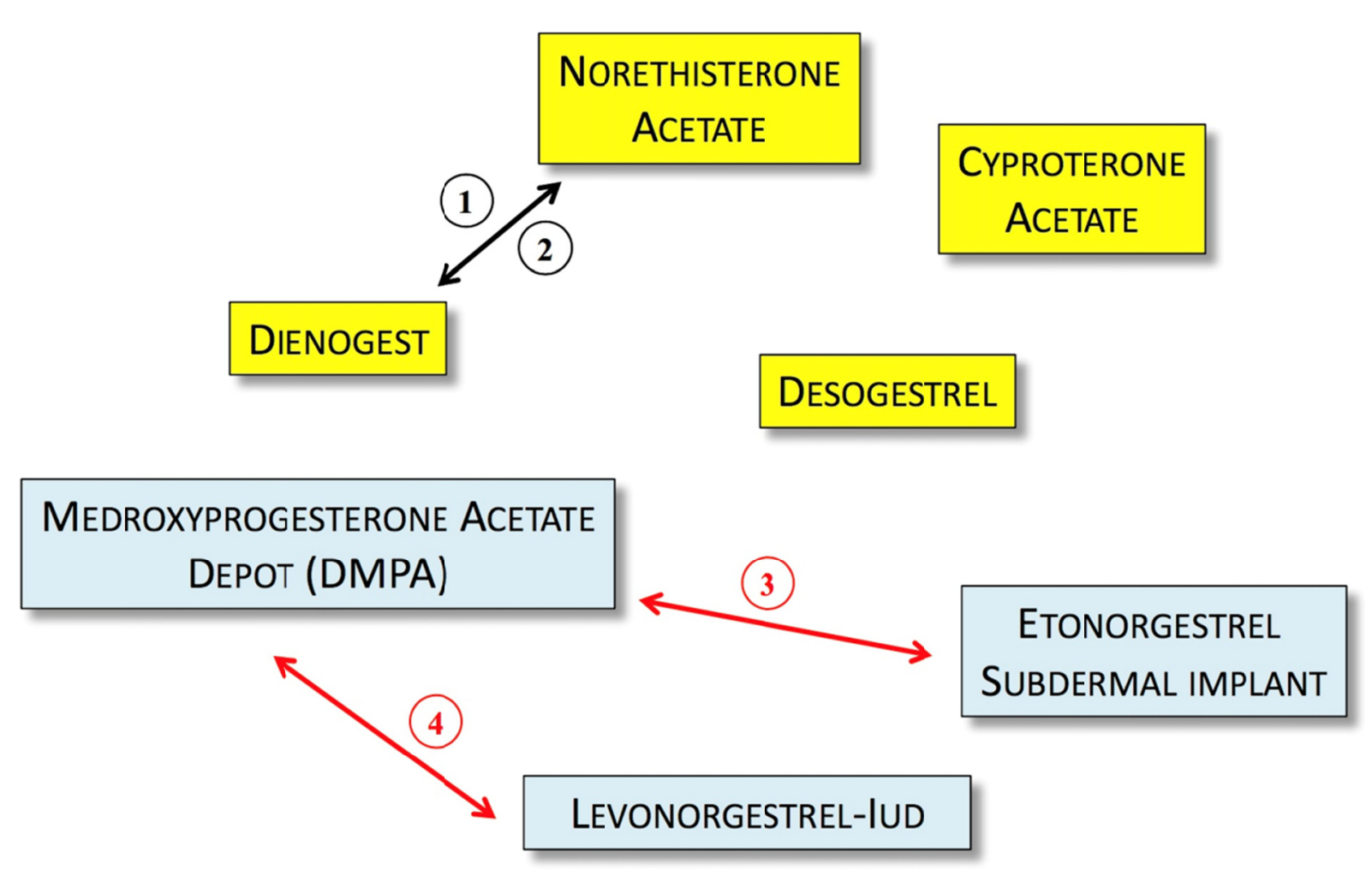




\section{REFERENCES}

1. Vercellini P, Buggio L, Berlanda N, et al. Estrogen-progestins and progestins for the management of endometriosis. Fertil Steril 2016;1552-1571.e2.

2. Vercellini P, Viganò P, Somigliana E, et al. Endometriosis: pathogenesis and treatment. Nat Rev Endocrinol 2014;10:261-75.

3. Ballard KD, Seaman HE, de Vries CS, et al. Can symptomatology help in the diagnosis of endometriosis? Findings from a national case-control study--Part 1. BJOG 2008;115:13821391.

4. Howard FM. Endometriosis and mechanisms of pelvic pain. J Min Invas Gynecol 2009;16:540-550.

5. Porpora MG, Koninckx PR, Piazze J, et al. Correlation between endometriosis and pelvic pain. J Am Assoc Gynecol Laparosc 1999;6:429-434.

6. Practice Committee of the American Society for Reproductive Medicine. Treatment of pelvic pain associated with endometriosis: a committee opinion. Fertil Steril 2014;101:927935.

7. Gezer A, Oral E. Progestin therapy in endometriosis. Womens Health 2015;11:643-652.

8. Reis FM, Petraglia F, Taylor RN. Endometriosis: hormone regulation and clinical consequences of chemotaxis and apoptosis. Hum Reprod Update 2013;19:406-418.

9. Vercellini P, Crosignani P, Somigliana E. The 'incessant menstruation' hypothesis: a mechanistic ovarian cancer model with implications for prevention. Hum Reprod 2011;26:2262-2273. 
10. Casper RF. Progestin-only pills may be a better first-line treatment for endometriosis than combined estrogen-progestin contraceptive pills. Fertil Steril 2017. Doi: 10.1016/j.fertnstert.2017.01.003.

11. Berlanda N, Somigliana E, Vigano P, et al. Safety of medical treatments for endometriosis. Expert Opin Drug Saf 2016;15:21-30.

12. Morotti M, Remorgida V, Venturini PL, et al. Progestogen-only contraceptive pill compared with combined oral contraceptive in the treatment of pain symptoms caused by endometriosis in patients with migraine without aura. Eur J Obstet Gynecol Reprod Biol 2014;179:63-8.

13. Vercellini P, Pietropaolo G, de Giorgi O, et al. Treatment of symptomatic rectovaginal endometriosis with an estrogen progestogen combination versus low-dose norethindrone acetate. Fertil Steril 2005;84:1375-1387

14. Ferrero S, Camerini G, Ragni N, et al. Norethisterone acetate in the treatment of colorectal endometriosis: a pilot study. Hum Reprod 2010;25:94-100.

15. Vercellini P, Somigliana E, Consonni D, et al. Surgical versus medical treatment for endometriosis-associated severe deep dyspareunia: I. Effect on pain during intercourse and patient satisfaction. Hum Reprod 2012;27:3450-3459.

16. Vercellini P, Frattaruolo MP, Somigliana E, et al. Surgical versus low-dose progestin treatment for endometriosis-associated severe deep dyspareunia II: effect on sexual functioning, psychological status and health-related quality of life. Hum Reprod 2013;28:1221-1230.

17. Chu MC, Zhang X, Gentzschein E, et al. Formation of ethinyl estradiol in women during treatment with norethindrone acetate. J Clin Endocrinol Metab 2007;92:2205-7. 
18. Chwalisz K, Surrey E, Stanczyk FZ. The hormonal profile of norethindrone acetate: rationale for add-back therapy with gonadotropin-releasing hormone agonists in women with endometriosis. Reprod Sci 2012;19:563-571.

19. Muneyyirci-Delale O, Karacan M. Effect of norethindrone acetate in the treatment of symptomatic endometriosis. Int J Fertil Womens Med 1998;43:24-27.

20. Kaser DJ, Missmer SA, Berry KF, et al. Use of norethindrone acetate alone for postoperative suppression of endometriosis symptoms. J Pediatr Adolesc Gynecol 2012;25:105-108.

21. Vercellini P, Bracco B, Mosconi P, et al. Norethindrone acetate or dienogest for the treatment of symptomatic endometriosis: a before and after study. Fertil Steril 2016;105:734-743.e3.

22. Bizzarri N, Remorgida V, Leone Roberti Maggiore U. Dienogest in the treatment of endometriosis. Expert Opin Pharmacother 2014;15:1889-1902. * Interesting review on the use of dienogest for the management of endometriosis.

23. Foster RH, Wilde MI. Dienogest. Drugs 1998;56:825-833

24. Lee DY, Lee JY, Seo JW, et al. Gonadotropin-releasing hormone agonist with add-back treatment is as effective and tolerable as dienogest in preventing pain recurrence after laparoscopic surgery for endometriosis. Arch Gynecol Obstet 2016;294:1257-1263.

25. Momoeda M, Harada T, Terakawa N, et al. Long-term use of dienogest for the treatment of endometriosis. J Obstet Gynaecol Res 2009;35:1069-1076.

26. Strowitzki T, Marr J, Gerlinger C, et al. Dienogest is as effective as leuprolide acetate in treating the painful symptoms of endometriosis: a 24-week, randomized, multicentre, open- 
label trial. Hum Reprod 2010;25:633-64. ** This is an important study that compares DNG with leuprolide acetate.

27. Strowitzki T, Faustmann T, Gerlinger C, et al. Dienogest in the treatment of endometriosisassociated pelvic pain: a 12-week, randomized, double-blind, placebo-controlled study. Eur J Obstet Gynecol Reprod Biol 2010;151:193-198.

28. Cosson M, Querleu D, Donnez J, et al. Dienogest is as effective as triptorelin in the treatment of endometriosis after laparoscopic surgery: results of a prospective, multicenter, randomized study. Fertil Steril 2002;77:684-692

29. Harada T, Momoeda M, Taketani Y, et al. Dienogest is as effective as intranasal buserelin acetate for the relief of pain symptoms associated with endometriosis: a randomized, doubleblind, multicenter, controlled trial. Fertil Steril 2009;91:675-81* This is an important study that compares DNG and buserelin acetate.

30. Takaesu Y, Nishi H, Kojima J, et al. Dienogest compared with gonadotropin-releasing hormone agonist after conservative surgery for endometriosis. J Obstet Gynaecol Res 2016;42:1152-1158.

31. Oh ST. The Comparison Between 2mg Dienogest and High-Dose Medroxyprogesterone Acetate on Oral Treatment of Endometriosis. J Minim Invasive Gynecol 2015;22:S170.

32. Morotti M, Sozzi F, Remorgida V, et al. Dienogest in women with persistent endometriosisrelated pelvic pain during norethisterone acetate treatment. Eur J Obstet Gynecol Reprod Biol 2014;183:188-192. * This is an interesting study that compares NETA and DNG.

33. Leyland N, Casper R, Laberge P, et al. Medical management of pain associated with endometriosis. Journal of Obstetrics and Gynaecology Canada 2010;32:S9-S14. 
34. Caruso S, Iraci M, Cianci S. Quality of life and sexual function of women affected by endometriosis-associated pelvic pain when treated with dienogest. J Endocrinol Invest $2015 ; 38: 1211-1218$.

35. Angioni S, Nappi L, Pontis A. Dienogest. A possible conservative approach in bladder endometriosis. Results of a pilot study. Gynecol Endocrinol 2015;31:406-408.

36. Harada M, Osuga Y, Izumi G, et al. Dienogest, a new conservative strategy for extragenital endometriosis: a pilot study. Gynecol Endocrinol 2011;27:717-720.

37. Leonardo-Pinto JP, Benetti-Pinto CL, Cursino K, et al. Dienogest and deep infiltrating endometriosis: The remission of symptoms is not related to endometriosis nodule remission. Eur J Obstet Gynecol Reprod Biol 2017; 211:108-111.

38. Strowitzki T, Faustmann T, Gerlinger C. Safety and tolerability of dienogest in endometriosis: pooled analysis from the European clinical study program. Int J Womens Health 2015;7:393-401.

39. Schindler AE, Christensen B, Henkel A, et al. High-dose pilot study with the novel progestogen dienogestin patients with endometriosis. Gynecol Endocrinol 2006;22:9-17.

40. Benagiano G, Primiero FM. Seventy-five microgram desogestrel minipill, a new perspective in estrogen-free contraception. Ann N Y Acad Sci 2003;997:163-73.

41. Collaborative Study Group on the desogestrel-containing progestogen-only pill. A doubleblind study comparing the contraceptive efficacy, acceptability and safety of two progestogen-only pills containing desogestrel $75 \mathrm{mcg} /$ day or levonorgestrel $30 \mathrm{mcg} / \mathrm{day}$. Eur J Contracept Reprod Health Care 1998;3:169-178. 
42. Razzi S, Luisi S, Ferretti C, et al. Use of a progestogen only preparation containing desogestrel in the treatment of recurrent pelvic pain after conservative surgery for endometriosis. Eur J Obstet Gynecol Reprod Biol 2007;135:188-190.

43. Remorgida V, Abbamonte LH, Ragni N, et al. Letrozole and desogestrel-only contraceptive pill for the treatment of stage IV endometriosis. Aust N Z J Obstet Gynaecol 2007;47:222225.

44. Leone Roberti Maggiore U, Remorgida V, Scala C, et al. Desogestrel-only contraceptive pill versus sequential contraceptive vaginal ring in the treatment of rectovaginal endometriosis infiltrating the rectum: a prospective open-label comparative study. Acta Obstet Gynecol Scand 2014;93:239-247. * This is an interesting study that compares DSG and contraceptive vaginal ring.

45. Morotti M, Remorgida V, Venturini PL, et al. Progestin-only contraception compared with extended combined oral contraceptive in women with migraine without aura: a retrospective pilot study. Eur J Obstet Gynecol Reprod Biol 2014;183:178-182.

46. Moran C, Alcivia JC, Garcia-Hernandez E, et al. Treatment of endometriosis with cyproterone acetate. Preliminary report. Arch Med Res 1996;27:535-538.

47. Vercellini P, De Giorgi O, Mosconi P, et al. Cyproterone acetate versus a continuous monophasic oral contraceptive in the treatment of recurrent pelvic pain after conservative surgery for symptomatic endometriosis. Fertil Steril 2002;77:52-61.

48. American College of Obstetricians and Gynecologists (ACOG). Committee Opinion No. 602. Depot medroxyprogesterone acetate and bone effects. Obstet Gynecol 2014;123:1398402. 
49. Vercellini P, De Giorgi O, Oldani S, et al. Depot medroxyprogesterone acetate versus an oral contraceptive combined with very-low-dose danazol for long-term treatment of pelvic pain associated with endometriosis. Am J Obstet Gynecol 1996;175:396-401

50. Crosignani PG, Luciano A, Ray A, et al. Subcutaneous depot medroxyprogesterone acetate versus leuprolide acetate in the treatment of endometriosis-associated pain. Hum Reprod 2006;21:248-256. * This is an important study comparing subcutaneous DMPA and leuprolide acetate.

51. Schlaff WD, Carson SA, Luciano A, et al. Subcutaneous injection of depot medroxyprogesterone acetate compared with leuprolide acetate in the treatment of endometriosis-associated pain. Fertil Steril 2006;85:314-325. * This is an important study comparing subcutaneous DMPA and leuprolide acetate.

52. Wong AY, Tang LC, Chin RK. Levonorgestrel-releasing intrauterine system (Mirena) and Depot medroxyprogesterone acetate (Depoprovera) as long-term maintenance therapy for patients with moderate and severe endometriosis: a randomised controlled trial. Aust N Z J Obstet Gynaecol 2010;50:273-279.

53. Cundy T, Cornish J, Roberts H, et al. Spinal bone density in women using depot medroxyprogesterone contraception. Obstet Gynecol 1998;92:569-573.

54. Scholes D, Lacroix AZ, Ott SM, et al. Bone mineral density in women using depot medroxyprogesterone acetate for contraception. Obstet Gynecol 1999;93:233-238.

55. Berenson AB, Radecki CM, Grady JJ, et al. A prospective, controlled study of the effects of hormonal contraception on bone mineral density. Obstet Gynecol 2001;98:475-582.

56. Scholes D, Lacroix AZ, Ichikawa LE, et al. Injectable hormone contraception and bone density: results from a prospective study. Epidemiology 2002;13:581-587. 
57. Cromer BA. Bone mineral density in adolescent and young adult women on injectable or oral contraception. Curr Opin Obstet Gynecol 2003;15:353-357.

58. Busen NH, Britt RB, Rianon N. Bone mineral density in a cohort of adolescent women using depot medroxyprogesterone acetate for one to two years. J Adolesc Health $2003 ; 32: 257-259$.

59. Clark MK, Sowers MR, Nichols S, et al. Bone mineral density changes over two years in first-time users of depot medroxyprogesterone acetate. Fertil Steril 2004;82:1580-1586.

60. Lara-Torre E, Edwards CP, Perlman S, et al. Bone mineral density in adolescent females using depot medroxyprogesterone acetate. J Pediatr Adolesc Gynecol 2004;17:17-21.

61. Scholes D, Lacroix AZ, Ichikawa LE, et al. Change in bone mineral density among adolescent women using and discontinuing depot medroxyprogesterone acetate contraception. Arch Pediatr Adolesc Med 2005;159:139-144.

62. Modesto W, Bahamondes MV, Bahamondes L. Prevalence of Low Bone Mass and Osteoporosis in Long-Term Users of the Injectable Contraceptive Depot Medroxyprogesterone Acetate. J Womens Health 2015;24:636-640. * Interesting paper on the risk of bone loss and osteoporosis in log-term users of DMPA.

63. Kaunitz AM, Arias R, McClung M. Bone density recovery after depot medroxyprogesterone acetate injectable contraception use. Contraception 2008;77:67-76.

64. Cromer BA, Bonny AE, Stager M, et al. Bone mineral density in adolescent females using injectable or oral contraceptives: a 24-month prospective study. Fertil Steril 2008;90:20602070. 
65. Harel Z, Johnson CC, Gold MA, et al. Recovery of bone mineral density in adolescents following the use of depot medroxyprogesterone acetate contraceptive injections. Contraception 2010;81:281-291.

66. Food and Drugs Administration (FDA). 2004. Pfizer update information for Depo-provera. Available at:

http://www.fda.gov/downloads/Safety/MedWatch/SafetyInformation/SafetyAlertsforHuman MedicalProducts/UCM166395.pdf [Last accessed 4 February 2017].

67. Health Canada Website. Health Canada Endorsed Important Safety Information on DEPOPROVERA* (medroxyprogesterone acetate). Available at:

http://www.healthycanadians.gc.ca/recall-alert-rappel-avis/hc-sc/2004/14252a-eng.php [Last accessed 4 February 2017].

68. Kaunitz AM, Darney PD, Ross D, et al. Subcutaneous DMPA vs. intramuscular DMPA: a 2year randomized study of contraceptive efficacy and bone mineral density. Contraception 2009;80:7-17.

69. Veestegaard P, Rejnmark L, Mosekilde L. The effects of depot medroxyprogesterone acetate and intrauterine device use on fracture risk in Danish women. Contraception 2008;78:459464.

70. Meier C, Brauchli YB, Jick SS, et al. Use of depot medroxyprogesterone acetate and fracture risk. J Clin Endocrinol Metab 2010;95:4909-4916.

71. Lanza LL, McQuay LJ, Rothman KJ, et al. Use of depot medroxyprogesterone acetate contraception and incidence of bone fracture. Obstet Gynecol 2013;121:593-600.

72. D'Arcangues C. WHO statement on hormonal contraception and bone health. Contraception $2006 ; 73: 443-444$. 
73. Luukkainen T, Lähteenmäki P, Toivonen J. Levonorgestrel-releasing intrauterine device. Ann Med 1990:22:85-90.

74. Viganò P, Somigliana E, Vercellini P. Levonorgestrel-releasing intrauterine system for the treatment of endometriosis: biological and clinical evidence. Womens Health 2007;3:207214.

75. Barbosa I, Bakos O, Olsson SE, et al. Ovarian function during use of a levonorgestrelrealising IUD. Contraception 1990;42:51-66.

76. Gomes MK, Rosa-e-Silva JC, Garcia CB, et al. Effects of the levonorgestrel-releasing intrauterine system on cell proliferation, Fas expression and steroid receptors in endometriosis lesions and normal endometrium. Hum Reprod 2009;24:2736-45.

77. Engemise SL, Willets JM, Taylor HM, et al. Changes in glandular and stromal estrogen and progesterone receptor isoform expression in eutopic and ectopic endometrium following treatment with the levonorgestrel-releasing intrauterine system. Eur J Obestet Gynecol Reprod Biol 2011;157:101-6.

78. Fedele L, Bianchi S, Zanconato G, et al. Use of a levonorgestrel-releasing intrauterine device in the treatment of rectovaginal endometriosis. Fertil Steril 2001;75:485-488.

79. Vercellini P, Frontino G, De Giorgi O, et al. Comparison of a levonorgestrel-releasing intrauterine device versus expectant management after conservative surgery for symptomatic endometriosis: a pilot study. Fertil Steril 2003;80:305-309.

80. Petta CA, Ferriani RA, Abrao MS, et al. Randomized clinical trial of a levonorgestrelreleasing intrauterine system and a depot $\mathrm{GnRH}$ analogue for the treatment of chronic pelvic pain in women with endometriosis. Hum Reprod 2005;20:1993-1998. * This is an important study comparing LNG-IUS and GnRHa. 
81. Ferreira RA, Vieira CS, Rosa-E-Silva JC, et al. Effects of the levonorgestrel-releasing intrauterine system on cardiovascular risk markers in patients with endometriosis: a comparative study with the GnRH analogue. Contraception 2010;81:117-122.

82. Bayoglu Tekin Y, Dilbaz B, Altinbas SK, et al. Postoperative medical treatment of chronic pelvic pain related to severe endometriosis: levonorgestrel-releasing intrauterine system versus gonadotropin-releasing hormone analogue. Fertil Steril 2011;95:492-496.

83. Tanmahasamut $\mathrm{P}$, Rattanachaiyanont M, Angsuwathana S, et al. Postoperative levonorgestrel-releasing intrauterine system for pelvic endometriosis-related pain: a randomized controlled trial. Obstet Gynecol 2012;119:519-526.

84. Chen YJ, Hsu TF, Huang BS, et al. Postoperative maintenance levonorgestrel-releasing intrauterine system and endometrioma recurrence A randomized controlled study. Am $\mathrm{J}$ Obstet Gynecol 2017;216:582.e1-582.e9. ** Important paper on the risk of endometrioma recurrence with LNG-IUS.

85. Lockhat FB, Emembolu JO, Konje JC. The efficacy, side-effects and continuation rates in women with symptomatic endometriosis undergoing treatment with an intra-uterine administered progestogen (levonorgestrel): a 3 year follow-up. Hum Reprod 2005;20:789793.

86. Vercellini P, Somigliana E, Viganò P, et al. 'Blood On The Tracks' from corpora lutea to endometriomas. BJOG 2009:116:366-371.

87. Kriplani A, Awasthi D, Kulshrestha V, et al. Efficacy of the levonorgestrel-releasing intrauterine system in uterine leiomyoma. Int J Gynaecol Obstet 2012;116:35-38.

88. Morelli M, Sacchinelli A, Ventturella R, et al. Postoperative administration of dienogest plus estradiol valerate versus levonorgestrel-releasing intrauterine device for prevention of 
pain relapse and disease recurrence in endometriosis patients. J Obstet Gyneaecol Res 2013;29:985-990.

89. Cho S, Jung JA, Lee Y, et al. Postoperative levonorgestrel-releasing intrauterine system versus oral contraceptives after gonadotropin-releasing hormone agonist treatment for preventing endometrioma recurrence. Acta Obstet Gynecol Scand 2014;93:38-44.

90. Kim ML, Cho YJ, Kim MK, et al. The efficacy of long-term maintenance therapy with a levonorgestrel-releasing intrauterine system for prevention of ovarian endometrioma recurrence. Int J Gynaecol Obstet 2016;134:256-299.

91. McNicholas C, Maddipati R, Zhao Q, et al. Use of the etonogestrel implant and levonorgestrel intrauterine device beyond the U.S. Food and Drug Administration-approved duration. Obstet Gynecol 2015;125:599-604.

92. Ali M, Akin A, Bahamondes L, et al. Extended use up to 5 years of the etonogestrelreleasing subdermal contraceptive implant: comparison to levonorgestrel-releasing subdermal implant. Hum Reprod 2016;31:2491-2498.

93. Yisa SB, Okenwa A $\widehat{A}$, Husemeyer RP. Treatment of endometriotic catamenial haemoptysis with etonogestrel subdermal implant. BJOG 2004;111:385-386.

94. Yisa SB, Okenwa AA, Husemeyer RP. Treatment of pelvic endometriosis with etonogestrel subdermal implant (Implanon). J Fam Plann Reprod Health Care 2005;31:67-70.

95. Al-Jefout M, Palmer J, Fraser IS. Simultaneous use of a levonorgestrel intrauterine system and an etonogestrel subdermal implant for debilitating adolescent endometriosis. Aust N Z J Obstet Gynaecol 2007;47:247-249.

96. Ponpuckdee J, Taneepanichskul S. The effects of implanon in the symptomatic treatment of endometriosis. J Med Assoc Thai 2005;88 Suppl 2:S7-10. 
97. Walch K, Unfried G, Huber J, et al. Implanon versus medroxyprogesterone acetate: effects on pain scores in patients with symptomatic endometriosis--a pilot study. Contraception. 2009;79:29-34.

98. Beerthuizen R, van Beek A, Massai R, et al. Bone mineral density during long-term use of the progestagen contraceptive implant Implanon compared to a non-hormonal method of contraception. Hum Reprod 2000;15:118-122.

99. Bahamondes L, Monteiro-Dantas C, Espejo-Arce X, et al. A prospective study of the forearm bone density of users of etonorgestrel- and levonorgestrel-releasing contraceptive implants. Hum Reprod. 2006;21:466-470.

100. Food and Drugs Administration (FDA). 2016. Implanon (etonogestrel) implants.

Detailed View: Safety Labeling Changes Approved by FDA Center for Drug Evaluation and Research (CDER) Available at:

https:/www.fda.gov/safety/medwatch/safetyinformation/ucm400440.htm [Last accessed 5 February 2017].

101. Agenzia Italiana del Farmaco AIFA, Nota Informativa Importante su Nexplanon (impianto contenente etonogestrel) (10/11/2016). Available online at http://www.aifa.gov.it/sites/default/files/DHPC_letter_Nexplanon_10.11.2016.pdf [Last accessed 6 February 2017].

102. Vercellini P. Endometriosis: the elusive gray area between evidence-based and evidencebiased medicine. Fertil Steril. 2014;101:45-6.

103. Brown J, Farquar C. Endometriosis: an overview of Cochrane Reviews. Cochrane Database Syst Rev 2014;3:CD009590. 
104. Alexander NJ, Baker E, Kaptein M, et al. Why consider vaginal drug administration? Fertil Steril 2004;82:1-12.

105. Bedaiwy MA, Alfaraj S, Yong P, et al. New developments in the medical treatment of endometriosis. Fertil Steril 2017;107:555-565.

106. Vercellini P, Giudice LC, Evers JK, et al. Reducing low-value care in endometriosis between limited evidence and unresolved issues: a proposal. Hum Reprod 2015;30:19962004. 
Table 1. List of progestins utilized for medical treatment of endometriosis.

\begin{tabular}{|l|l|l|l|}
\hline Drug & Chemical structure & Route of administration & Cost $^{\text {a }}$ \\
\hline Cyproterone acetate (CPA) & $17-\mathrm{OH}$ progesterone derivative & Oral & $24,00 €(25 \mathrm{pills} \mathrm{of} \mathrm{50} \mathrm{mg)}$ \\
\hline Desogestrel (DSG) & 19 -nortesterone derivative & Oral & $9,90-15,40 €(28 \mathrm{pills})$ \\
\hline Dienogest (DNG) & 19 -nortesterone derivative & Oral & $56,00 €(28$ pills $)$ \\
\hline Etonogestrel (ENG) & 19 -nortesterone derivative & Subdermal implant & $195,00 €($ lifespan 3 years) \\
\hline Levonorgestrel (LNG) & 19 -nortesterone derivative & Intrauterine device & $242,00 €($ lifespan 5 years) \\
\hline Depot Medroxyprogesterone acetate (DMPA) & $17-$-OH progesterone derivative & Intramuscular, subcutaneous & $8,70 €($ lifespan 3 months $)$ \\
\hline Norethisterone acetate (NETA) & 19 -nortesterone derivative & Oral & $5,68 €(30$ pills of 10 mg) \\
\hline
\end{tabular}

${ }^{a}$ Based on the Italian market 
Table 2. Effect of dienogest (DNG), as assessed in comparative studies on the treatment of symptomatic endometriosis (literature data, 2002-2016).

\begin{tabular}{|c|c|c|c|c|c|c|c|}
\hline Source & Study design & $\begin{array}{l}\text { Number } \\
\text { of } \\
\text { patients } \\
\text { enrolled }\end{array}$ & Study drug & Comparator & $\begin{array}{l}\text { Treatment } \\
\text { period }\end{array}$ & $\begin{array}{l}\text { Follow-up } \\
\text { period }\end{array}$ & Outcome \\
\hline $\begin{array}{l}\text { Cosson et al., } 2002 \\
{[28]}\end{array}$ & $\mathrm{RCT}$ & 142 & $\begin{array}{l}\text { DNG } 2 \text { mg/day per os } \\
(\mathrm{n}=74)\end{array}$ & $\begin{array}{l}\text { Triptorelin } 3.75 \mathrm{mg} \\
\text { depot i.m. } \\
\text { injections/28 days } \\
(\mathrm{n}=68)\end{array}$ & & $\begin{array}{l}12 \text { months } \\
\text { (reproductive } \\
\text { outcome } \\
\text { only) }\end{array}$ & $\begin{array}{l}\text { Similar postoperative pain } \\
\text { relief during treatment; no } \\
\text { pain evaluation at } 12 \\
\text { months follow-up }\end{array}$ \\
\hline $\begin{array}{l}\text { Harada et al., } 2009 \\
\text { [29] }\end{array}$ & $\mathrm{RCT}$ & 271 & $\begin{array}{l}\text { DNG } 2 \mathrm{mg} \text { /day per os } \\
(\mathrm{n}=137)\end{array}$ & $\begin{array}{l}\text { Buserelin } 900 \\
\text { mg/day i.n. } \\
(\mathrm{n}=134)\end{array}$ & 6 months & No follow-up & $\begin{array}{l}\text { Similar pain relief and } \\
\text { improvement in QoL. More } \\
\text { bleeding, but less hypo- } \\
\text { estrogenic side effects and } \\
\text { BMD loss with DNG. }\end{array}$ \\
\hline $\begin{array}{l}\text { Strowitzki et al., } \\
2010 \text { [26] }\end{array}$ & $\mathrm{RCT}$ & 252 & $\begin{array}{l}\text { DNG } 2 \mathrm{mg} \text { /day per os } \\
(\mathrm{n}=124)\end{array}$ & $\begin{array}{l}\text { Leuprolide } 3.75 \mathrm{mg} \\
\text { depot i.m. } \\
\text { injections/28 days } \\
(\mathrm{n}=128)\end{array}$ & 6 months & No follow-up & $\begin{array}{l}\text { Similar pain relief. Higher } \\
\text { improvement in QoL with } \\
\text { DNG. More bleeding but } \\
\text { less hypo-estrogenic side } \\
\text { effects and BMD loss with } \\
\text { DNG. }\end{array}$ \\
\hline $\begin{array}{l}\text { Morotti et al., } 2014 \\
\text { [32] }\end{array}$ & $\begin{array}{l}\text { Open-label } \\
\text { prospective } \text { study }^{\mathrm{a}}\end{array}$ & 25 & $\begin{array}{l}\text { DNG } 2 \mathrm{mg} / \text { day per os } \\
(\mathrm{n}=25)\end{array}$ & $\begin{array}{l}\text { NETA } 2.5 \mathrm{mg} / \text { day } \\
\text { per os }(\mathrm{n}=25)\end{array}$ & $\begin{array}{l}12 \text { months } \\
\text { ( } 6 \text { months } \\
\text { of NETA + } \\
6 \text { months } \\
\text { of DNG) }\end{array}$ & No follow-up & $\begin{array}{l}\text { Improvement of pain } \\
\text { symptoms, sexual function, } \\
\text { QoL and satisfaction with } \\
\text { DNG }\end{array}$ \\
\hline Oh et al., 2015 [31] & Retrospective & 218 & $\begin{array}{l}\text { DNG } 2 \mathrm{mg} / \text { day per os } \\
(\mathrm{n}=98)\end{array}$ & $\begin{array}{l}\text { MPA } 30-60 \mathrm{mg} / \text { day } \\
\text { per os }(\mathrm{n}=120)\end{array}$ & 6 months & No follow-up & $\begin{array}{l}\text { Higher pain relief with } \\
\text { DNG. More bleeding, } \\
\text { alopecia, and headache } \\
\text { with DNG. More weight } \\
\text { gain, depression and breast } \\
\text { tenderness with MPA. }\end{array}$ \\
\hline
\end{tabular}




\begin{tabular}{|c|c|c|c|c|c|c|c|}
\hline Source & Study design & $\begin{array}{l}\text { Number } \\
\text { of } \\
\text { patients } \\
\text { enrolled }\end{array}$ & Study drug & Comparator & $\begin{array}{l}\text { Treatment } \\
\text { period }\end{array}$ & $\begin{array}{l}\text { Follow-up } \\
\text { period }\end{array}$ & Outcome \\
\hline $\begin{array}{l}\text { Takaesu et al., } \\
2016[30]\end{array}$ & $\mathrm{RCT}$ & 111 & $\begin{array}{l}\text { DNG } 2 \mathrm{mg} / \text { day per os } \\
(n=56)\end{array}$ & $\begin{array}{l}\text { Goserelin } 1.8 \mathrm{mg} \\
\text { depot s.c. } \\
\text { injections/28 days } \\
(n=55)\end{array}$ & 24 weeks & 24 months & $\begin{array}{l}\text { No difference in post- } \\
\text { operative endometriosis } \\
\text { recurrence rate. Similar } \\
\text { pain relief, but fewer side } \\
\text { effects with DNG. }\end{array}$ \\
\hline $\begin{array}{l}\text { Vercellini et al., } \\
2016[21]\end{array}$ & $\begin{array}{l}\text { Before-after } \\
\text { study }\end{array}$ & 90 & $\begin{array}{l}\text { DNG } 2 \mathrm{mg} / \text { day per os } \\
(n=90)\end{array}$ & $\begin{array}{l}\text { NETA } 2.5 \mathrm{mg} / \text { day } \\
\text { per os }(n=90)\end{array}$ & & No follow-up & $\begin{array}{l}\text { Similar satisfaction with } \\
\text { treatment, frequency of } \\
\text { irregular bleeding and pain } \\
\text { relief. Comparable } \\
\text { improvements in QoL and } \\
\text { sexual functioning. Better } \\
\text { tolerability with dienogest. } \\
\text { Higher discontinuation rate } \\
\text { with DNG (owing to drug } \\
\text { cost) }\end{array}$ \\
\hline Lee et al. 2016 [24] & $\mathrm{RCT}$ & 64 & $\begin{array}{l}\text { DNG } 2 \mathrm{mg} \text { /day per os } \\
(n=36)\end{array}$ & $\begin{array}{l}\text { Leuprorelin acetate } \\
3.75 \mathrm{mg} \text { s.c. } \\
\text { injections } / 28 \text { days }+ \\
\text { NETA } 0.5 \mathrm{mg} / \text { day } \\
\text { or estradiol } \\
1 \mathrm{mg} / \text { day per os } \\
(n=28)\end{array}$ & 6 months & No follow-up & $\begin{array}{l}\text { Similar pain relief. } \\
\text { Comparable QoL } \\
\text { improvements. Similar } \\
\text { lumbar spine BMD loss in } \\
\text { both groups }(-2.5 \% \text { for } \\
\text { GnRHa plus add-back } \\
\text { therapy and }-2.3 \% \text { with } \\
\text { DNG) }\end{array}$ \\
\hline
\end{tabular}

${ }^{a}$ This study specifically selected patients with symptomatic rectovaginal endometriosis who had pain persistence and were unsatisfied after 6months of treatment with NETA.

BMD, bone mineral density; DNG, dienogest; i.m., intramuscular; i.n., intranasal; MPA, medroxyprogesterone acetate; NETA, norethisterone acetate; QoL, quality of life; RCT, randomized controlled trial; s.c., subcutaneous 
Table 3. Summary of randomized controlled trials on the use of LNG-IUS for the treatment of pain symptoms associated with endometriosis.

\begin{tabular}{|c|c|c|c|c|c|}
\hline Source & $\begin{array}{l}\text { Number } \\
\text { of } \\
\text { patients } \\
\text { enrolled }\end{array}$ & Study drug & Comparator & $\begin{array}{l}\text { Follow-up } \\
\text { period }\end{array}$ & Outcome \\
\hline Petta et al., 2005 [80] & 82 & $\begin{array}{l}\text { LNG-IUS } \\
(n=39)\end{array}$ & $\begin{array}{l}\text { Leuprolide } 3.75 \mathrm{mg} \text { depot i.m. } \\
\text { injections } / 28 \text { days }(n=43)\end{array}$ & 6 months & $\begin{array}{l}\text { Similar pain relief and psychological well-being. } \\
\text { More bleeding with LNG-IUS. }\end{array}$ \\
\hline Wong et al., 2010 [52] & 30 & $\begin{array}{l}\text { LNG-IUS } \\
(n=15)\end{array}$ & $\begin{array}{l}\text { DMPA } 150 \mathrm{mg} \text { i.m. injections/ } \\
\text { months }(n=15)\end{array}$ & 36 months & $\begin{array}{l}\text { Similar symptoms control and lesions recurrence } \\
\text { rates. Irregular vaginal bleeding common in both } \\
\text { group; frequency and severity of bleeding worse } \\
\text { with DMPA. Improvement of BMD with LNG- } \\
\text { IUS. Decline of BMD with DMPA. Better } \\
\text { compliance in LNG-IUS group. }\end{array}$ \\
\hline Ferreira et al., 2010 [81] & 44 & $\begin{array}{l}\text { LNG-IUS } \\
(n=22)\end{array}$ & $\begin{array}{l}\text { Leuprolide } 3.75 \mathrm{mg} \text { depot i.m. } \\
\text { injections/28 days }(n=21)\end{array}$ & 6 months & $\begin{array}{l}\text { Similar pain relief. Significant reduction in VCAM, } \\
\text { CRP, total cholesterol, triglycerides, LDL-C and } \\
\text { HDL-C levels in LNG-IUS group. }\end{array}$ \\
\hline $\begin{array}{l}\text { Tanmahasamut et al., } 2012 \\
\text { [83] }\end{array}$ & 55 & $\begin{array}{l}\text { LNG-IUS ( } n \\
=28)\end{array}$ & $\begin{array}{l}\text { Expectant management after } \\
\text { laparoscopic treatment of } \\
\text { endometriotic lesions }(n=27)\end{array}$ & 12 months & $\begin{array}{l}\text { Greater pain relief (dysmenorrhea and chronic } \\
\text { pelvic pain) with LNG-IUS. Similar dyspareunia } \\
\text { relief. Lower recurrence rate of dysmenorrhea in } \\
\text { LNG-IUS group. Improvement in QoL in women } \\
\text { treated with LNG-IUS. }\end{array}$ \\
\hline
\end{tabular}




\begin{tabular}{|l|l|l|l|l|l|}
\hline Source & $\begin{array}{l}\text { Number } \\
\text { of } \\
\text { patients } \\
\text { enrolled }\end{array}$ & Study drug & Comparator & $\begin{array}{l}\text { Follow-up } \\
\text { period }\end{array}$ & Outcome \\
\hline Chen YJ et al., 2017 [84] & 80 & $\begin{array}{l}\text { GnRHa 3.75 } \\
\text { mg depot } \\
\text { i.m. } \\
\text { injections/28 } \\
\text { days for 6 } \\
\text { months + } \\
\text { LNG-IUS }(n \\
=40)\end{array}$ & $\begin{array}{l}\text { GnRHa 3.75 mg depot i.m. } \\
\text { injections/28 days for 6 months }+ \\
\text { expectant management }(n=40)\end{array}$ & 30 months & $\begin{array}{l}\text { Similar endometrioma recurrence rate at 30 } \\
\text { months' follow-up between the two groups. Longer } \\
\text { duration to dysmenorrhea recurrence in LNG-IUS } \\
\text { group. Greater pain relief with LNG-IUS. Higher } \\
\text { analgesic use in control group. Greater reduction of } \\
\text { CA125 levels with LNG-IUS. Higher irregular } \\
\text { vaginal bleeding in LNG-IUS group. }\end{array}$ \\
\hline
\end{tabular}

DMPA, depot medroxyprogesterone acetate; LNG-IUS, levonorgestrel-releasing intrauterine system; QoL, quality of life; BMD, bone mineral density; VCAM, vascular cell adhesion molecule; CRP, C-reactive protein; LDL, low-density lipoprotein cholesterol; HDL, high-density lipoprotein cholesterol. 
Table 4. Advantages and disadvantages of progestins utilized for medical treatment of endometriosis.

\begin{tabular}{|c|c|c|}
\hline Drug & Advantages & Disadvantages \\
\hline Cyproterone acetate (CPA) & $\begin{array}{ll}\text { - } & \text { Improvement of pelvic pain symptoms } \\
\text { - } & \text { Regression of endometriotic lesions at } \\
& \text { second-look laparoscopy } \\
\text { - } & \text { No major variations in serum lipid profile } \\
\text { - } & \text { Low cost }\end{array}$ & $\begin{array}{l}\text { High percentage of women reporting a } \\
\text { decrease in libido among the side effect }\end{array}$ \\
\hline Depot Medroxyprogesterone acetate (DMPA) & $\begin{array}{ll}\text { - } & \text { Safe contraceptive method } \\
\text { - } & \text { Low cost } \\
\text { - } & \text { No-inferior to GnRHa in the management of } \\
& \text { pain symptoms }\end{array}$ & $\begin{array}{ll}\text { - } & \text { Prolonged, repeated and difficult to treat } \\
\text { breakthrough bleeding } \\
\text { - } \\
\text { - }\end{array}$ \\
\hline Desogestrel (DSG) & $\begin{array}{l}\text { - Safe contraceptive method, even during } \\
\text { breast-feeding } \\
\text { - Effective in the treatment of endometriosis } \\
\text { in patients with migraine }\end{array}$ & $\begin{array}{ll}- & \text { Breakthrough bleeding } \\
\text { - } & \text { Limited data }\end{array}$ \\
\hline Dienogest (DNG) & $\begin{array}{l}\text { - Superior to placebo and no-inferior to } \\
\text { GnRHa in the treatment of symptomatic } \\
\text { endometriosis } \\
\text { - Combines the pharmacological properties of } \\
\text { 19-nortestosterone and derivatives of } \\
\text { progesterone } \\
\text { Better tolerated than NETA }\end{array}$ & $\begin{array}{ll}\text { - } & \text { High cost } \\
\text { - } & \text { Inconsistent data on BMD } \\
\text { - } & \text { No RCTs against COC or other progestins }\end{array}$ \\
\hline Etonogestrel (ENG) & $\begin{array}{l}\text { Safe contraceptive method } \\
\text { Low-cost } \\
\text { - } \quad \text { Extended-use to } 5 \text { year } \\
\text { - Comparable to DMPA in the treatment of } \\
\text { symptomatic endometriosis }\end{array}$ & $\begin{array}{ll}\text { - } & \text { Limited data } \\
\text { - } & \text { Risk of site migration } \\
\text { - } & \text { Inconsistent data on BMD }\end{array}$ \\
\hline Levonorgestrel (LNG) & $\begin{array}{ll}\text { - } & \text { Safe contraceptive method } \\
\text { - } & \text { Low cost (spread in a 5-year lifespan) } \\
\text { - } & \text { Fewer adverse effects than systemic } \\
& \text { progestins }\end{array}$ & $\begin{array}{l}\text { - During the first months after insertion } \\
\text { menstrual irregularities may occur } \\
\text { - Does not inhibit ovulation, risk of } \\
\text { endometrioma recurrence }\end{array}$ \\
\hline
\end{tabular}




\begin{tabular}{|c|c|c|}
\hline Drug & Advantages & Disadvantages \\
\hline & $\begin{array}{l}\text { - No-inferior to GnRHa in the treatment of } \\
\text { symptomatic endometriosis }\end{array}$ & \\
\hline Norethisterone acetate (NETA) & $\begin{array}{ll}\text { - } & \text { Low cost } \\
\text { - } & \text { Partly metabolized to estrogens, with } \\
\text { positive effects on BMD } \\
\text { - } \quad \text { Improvement of pelvic pain symptoms } \\
\text { - } \quad \text { Effective in the treatment of deep } \\
\text { dyspareunia, in particular in those women } \\
\text { without deep lesions }\end{array}$ & $\begin{array}{l}\text { Principal side effects are breakthrough } \\
\text { bleeding, weight gain and decreased libido } \\
\text { Minor unfavorable changes in lipid profile } \\
\text { (in particular with dosages }>10 \mathrm{mg} / \mathrm{d} \text { ) }\end{array}$ \\
\hline
\end{tabular}

